\title{
A Prospective Study to Assess the Bone Marrow Aspiration for Findings of Patients with Hematological Disorders
}

\author{
Sushma Singh Rathore ${ }^{1}$ \\ ${ }^{1}$ Senior Demonstrator, Department of Pathology, Government Medical College, Dungarpur, Rajasthan, India.
}

\section{Abstract}

Background: Examination of bone marrow is beneficial procedure for the diagnosis of hematological and non-hematological diseases. Bone marrow aspiration singly is usually sufficive for the diagnosis of nutritional anemia, majority of the acute leukemia and Immune thrombocytic disorders. The present study was conducted with the aim to assess the bone marrow aspiration findings amongst subjects with hematological disorders. Subjects and Methods: The present cross sectional study was conducted in the department of pathology, Government Medical College, Dungarpur, Rajasthan (India) during a period of 2 years. Amongst all the subjects, peripheral smears, reticulocyte counts, sickling test and hemogram were obtained. Special stains Periodic acid Schiff staining was done for all subjects with acute lymphocytic leukemia, acute myeloid leukemia and Gaucher's disorder. Block positivity was shown amongst ALL cases. In subjects with Gaucher's disorder, Gaucher cells showed wrinkled tissue paper appearance using PAS staining. All the data thus obtained was arranged in a tabulated form and analyzed using SPSS software. Percentage of all the data was obtained. Results: The present study bone marrow aspiration was performed amongst 110 subjects and bone marrow biopsy was performed amongst 54 subjects. There were $48.2 \%$ cases of anemia, $14.5 \%(\mathrm{n}=16)$ cases of acute leukemia. In $10.9 \%$ of cases myeloproliferative disorders were observed and $1.8 \%$ cases had myelodysplastic syndrome. There were $20.4 \%$ cases of hyoplastic anemia. There were $11.1 \%$ subjects that showed normal results. NHL deposits and myelofibrosis was seen in 5.6\% cases each. ALL was diagnosed in 1 case. Conclusion: Aspiration of bone marrow is important for diagnosing, determining the prognosis and therapeutic response of different types of hematological and non hematological conditions.

Keywords: Aspiration, Bone Marrow, Hematological.

Corresponding Author: Dr. Sushma Singh Rathore, Senior Demonstrator, Department of Pathology, Government Medical College, Dungarpur, Rajasthan, India.

Received: April 2019

Accepted: May 2019

\section{Introduction}

Examination of bone marrow is beneficial procedure for the diagnosis of hematological and non-hematological diseases. The two most significant methodologies for the diagnosis of hematological diseases are aspiration of bone marrow and trephine biopsy. For the final interpretation of bone marrow the complete medical history, clinical results, peripheral blood smears and different other laboratory investigations are required. ${ }^{[1]}$ Bone marrow aspiration singly is usually sufficive for the diagnosis of nutritional anemia, majority of the acute leukemia and Immune thrombocytic disorders. Trephine biopsy provides an important diagnostic criteria amongst subjects with granulomatous disorders, myelofibrotic diseases and infiltrations of bone marrow. ${ }^{[2]}$ Bone marrow aspiration is important in elucidating better individual cell structure. On the contrary, biopsy is important for providing bone marrow architectural structures and distribution. ${ }^{[3]}$ The present study was conducted with the aim to assess the bone marrow aspiration findings amongst subjects with hematological disorders.

\section{Subjects and Methods}

The present cross sectional study was conducted in the department of pathology, Government Medical College, Dungarpur, Rajasthan (India) during a period of 2 years. All the subjects were informed about the study and a written consent was obtained from them in their vernacular language. Sampling of the patients through screening in different departments was done to enroll the patients in the study. For bone marrow aspiration, Leishman stain was used. For trephine biopsy, Hematoxylin and eosin stain was used. Amongst all the subjects, peripheral smears, reticulocyte counts, sickling test and hemogram were obtained. Special stains Periodic acid Schiff staining was done for all subjects with acute lymphocytic leukemia, acute myeloid leukemia and Gaucher's disorder. Block positivity was shown amongst ALL cases. In subjects with 
Gaucher's disorder, Gaucher cells showed wrinkled tissue paper appearance using PAS staining. Reticulin stain was performed in subjects with myelofibrosis and metastatic depositions. In myelofibrosis cases, trephine biopsy showed elevated reticulin network with coarse fibrillar appearance. Perl's stain was performed in all cases for evaluating iron stores.

Procedure for bone marrow aspiration: In all subjects, material was obtained from the posterior superior iliac spine that is the most appropriate and safe location for aspiration and biopsy both. Other sites that can be used are sternum and medial location of tibia. Salah's needle was castoff for the bone marrow aspiration procedure. Jamshidi's needle was used for the bone marrow biopsy technique. Complete blood evaluation, peripheral smear tests, reticulocyte count estimation, bone marrow aspiration was performed in 110 cases of hematological disorders, amongst them trephine biopsy was performed in 54 cases. All the data thus obtained was arranged in a tabulated form and analyzed using SPSS software. Percentage of all the data was obtained.

\section{Results}

The present study bone marrow aspiration was performed amongst 110 subjects and bone marrow biopsy was performed amongst 54 subjects. The age range of the subjects was 3-52 years and the mean age of 34.5 years. There were 60 males and 40 females.

\begin{tabular}{|c|c|c|}
\hline Disorder & Frequency & Percentage \\
\hline Anemias & 53 & 48.2 \\
\hline Acute leukemias & 16 & 14.5 \\
\hline $\begin{array}{l}\text { Myeloproliferative } \\
\text { disorders }\end{array}$ & 12 & 10.9 \\
\hline $\begin{array}{l}\text { Myelodysplastic } \\
\text { syndrome }\end{array}$ & 2 & 1.8 \\
\hline Plasma cell dyscrasias & 6 & 5.4 \\
\hline $\begin{array}{l}\text { Lymphoproliferative } \\
\text { disorders }\end{array}$ & 4 & 3.6 \\
\hline Platelet disorders & 8 & 7.2 \\
\hline Others & 3 & 2.7 \\
\hline Normal Study & 3 & 2.7 \\
\hline Inconclusive & 3 & 2.7 \\
\hline Total & 110 & 100 \\
\hline
\end{tabular}

Table 2: Diagnosis by trephine biopsy

\begin{tabular}{|l|l|l|}
\hline Diagnosis & Frequency & Percentage \\
\hline Erythroid Hyperplasia & 25 & 46.3 \\
\hline $\begin{array}{l}\text { Aplastic/ Hypoplastic } \\
\text { anemia }\end{array}$ & 11 & 20.4 \\
\hline Normal & 6 & 11.1 \\
\hline NHL deposits & 3 & 5.6 \\
\hline Myelofibrosis & 3 & 5.6 \\
\hline ALL & 1 & 1.8 \\
\hline Metastatic deposit & 2 & 3.7 \\
\hline Plasma cell dyscrasias & 1 & 1.8 \\
\hline $\begin{array}{l}\text { Reactive } \\
\text { thrombocytosis }\end{array}$ & 1 & 1.8 \\
\hline Inconclusive & 1 & 1.8 \\
\hline Total & 54 & 100 \\
\hline
\end{tabular}

[Table 1] shows the hematological diseases suffered by the subjects. There were $48.2 \%$ cases of anemia, $14.5 \% \quad(n=16)$ cases of acute leukemia. In $10.9 \%$ of cases myeloproliferative disorders were observed and $1.8 \%$ cases had myelodysplastic syndrome. Plasma cell dyscrasias was observed in 5.4\% cases. Lymphoproliferative disorders and platelet disorders were seen in $3.6 \%$ and $7.2 \%$ cases. There were $2.7 \%$ cases that showed inconclusive results.

[Table 2] shows the results of trephine biopsy. Erythroid hyperplasia was seen amongst $46.3 \%$ cases. There were $20.4 \%$ cases of hyoplastic anemia. There were $11.1 \%$ subjects that showed normal results. NHL deposits and myelofibrosis was seen in $5.6 \%$ cases each. ALL was diagnosed in 1 case. Metastatic deposits and plasma cell dyscrasias were seen on $3.7 \%$ and $1.8 \%$ cases respectively. There was only 1 case with inconclusive results.

\section{Discussion}

Bone marrow is intricated in various hematological and non-hematological diseases. The hematological disease like acute leukemia, myeloproliferative tumors, hematolymphoid tumors, nutritional deficiency disorders. On the contrary non-hematological diseases in which bone marrow is involved are infectious disorders infiltrating the marrow like tuberculosis, parasitic infestations and metastatic predispositions. ${ }^{[4]}$ Although, disorders of bone marrow show different clinical signs and symptoms and include the blood but peripheral picture of blood alone cannot show the type of diseased phenomenon. Based upon diagnosis alleged from the clinical signs and symptoms and peripheral blood smear view and bone marrow examination can be performed. Therefore, full hematological examination in diseases where bone marrow evaluation is indicated consist of smear from bone marrow aspirate and bone marrow trephine biopsy as an additional diagnostic measure. ${ }^{[5]}$ The bone marrow evaluation is valuable test in hematology practices. Aspiration and biopsy both are crucial procedures for diagnosing hematological and non-hematological diseased conditions. These investigations are also important during follow up of the subjects who underwent chemotherapy. ${ }^{[6,7]}$ The age range of the subjects was 3-52 years and the mean age of 34.5 years. There were 60 males and 40 females. There were $48.2 \%$ cases of anemia, $14.5 \%(n=16)$ cases of acute leukemia. In $10.9 \%$ of cases myeloproliferative disorders were observed and $1.8 \%$ cases had myelodysplastic syndrome. Plasma cell dyscrasias was observed in $5.4 \%$ cases. Lymphoproliferative disorders and platelet disorders were seen in $3.6 \%$ and $7.2 \%$ cases. There were $2.7 \%$ cases that showed inconclusive results. Erythroid hyperplasia was seen amongst $46.3 \%$ cases. There were $20.4 \%$ cases of hyoplastic anemia. There were $11.1 \%$ subjects that showed normal results. NHL deposits and myelofibrosis was seen in $5.6 \%$ cases each. ALL was diagnosed in 1 case. Metastatic deposits and plasma cell dyscrasias were seen on $3.7 \%$ and $1.8 \%$ cases respectively. There was only 1 case with inconclusive results. Comparable results were obtained by 
studies conducted by by Tilak et al in the year $1999,{ }^{[8]}$ Khodke et al. in the year $2001,{ }^{[9]}$ Khunger et al in the year 2002 and Jha et al. in the year 2008. ${ }^{[10]}$ The results were in contrast to the studies byKumar et al. ${ }^{[1]}$ and Das et al. ${ }^{[12]}$ as they Didn't include children in their study.The commonest sign for bone marrow aspiration was pancytopenia. In few cases biopsy can give a corroborative evidence to perform bone marrow aspiration. Kumar et al. ${ }^{[13]}$ concluded in his study that bone marrow aspiration and biopsy could be performed simultaneously amongst pancytopenic subjects when the diagnosis is indefinable. As per the recent studies by Chandra et al. ${ }^{[14]}$ Parajuli et al. ${ }^{[15]}$ and Khan et al. ${ }^{[16]}$ 2014 erythroid hyperplasia was one of the commonest diagnosis that was comparable to our study. A limitation associated with the bone marrow aspiration procedure is the mixing of the marrow with the blood of sinusoids that may not allow for the estimation of cellularity of marrow. Also, it is crucial that results of a 'dry tap' should never be discharged due to faulty procedure and always requires a marrow biopsy for future evaluation.

\section{Conclusion}

Aspiration of bone marrow is important for diagnosing, determining the prognosis and therapeutic response of different types of hematological and non-hematological conditions. This can be performed routinely and doesn't require any specialized equipment. The study clearly demonstrated the usefulness of bone marrow aspiration in different hematological diseases.

\section{References}

1. Brown DC, Gatter KC. The bone marrow trephine biopsy: a review of normal histology. Histopath. 1993;22:411-22.

2. Sola CM, Rimsza LM, Christensen RD. A bone marrow biopsy technique suitable for use in neonates. $\mathrm{Br} \mathrm{J}$ Hematol.
1999;107:458-60.

3. Brynes RK, Mckenna RW, Sundbeerg RD. Bone marrow aspiration and trephine biopsy: an approach to a thorough study. Am J Clin Pathol. 1978;70:753-9.

4. Neal S, Young. Aplastic anaemia, myelodysplasia and related bone marrow syndromes. In: Kasper, Braunwald, Fauci, Hauser, Longo, Jameson, editors. Harrison's Principles of Internal medicine(Vol. 1).16. New Delhi: McGraw Hill;2005.p.617.

5. Krause JR. An appraisal of the value of the bone marrow biopsy in the assessment of proliferative lesions of the bone marrow. Histopathology. 1983;7(5):627-44.

6. Riley RS, Hogan TF, Pavot DR, Forysthe R, Massey D, Smith $\mathrm{E}$, et al. A pathologist's perspective on bone marrow aspiration and biopsy; Performing a bone marrow examination. J Clin Lab Anal. 2004;18(2):70-9.

7. Islam A. Bone marrow aspiration prior to bone marrow core biopsy using the same bone marrow biopsy needle. A good or bad practice. J Clin Pathol. 2007;60:212-15.

8. Tilak V, Jain R. Pancytopenia: a clinico-hematologic analysis of 77 cases. Indian J Pathol Microbiol. 1999;42:399-404.

9. Khodke K, Marwah S, Buxi G, Yadav RB, Chaturvedi NK. Bone marrow examination in cases of pancytopenia. $\mathrm{J}$ Indian Acad Clin Med. 2001;2:55-9.

10. Jha A, Sayami G, Adhikari RC, Panta AD, Jha R. Bone Marrow Examination in Cases of Pancytopenia. J Nepal Med Assoc. 2008;47(169):12-7.

11. Kumar R, Kalra SP, Kumar H, Anand AC, Madan H. Pancytopenia: a six year study. J Assoc Physicians India. 2001;49:1078-81.

12. Santra G, Das BK. A cross-sectional study of the clinical profile and aetiological spectrum of pancytopenia in a tertiary care centre. Singapore Med J. 2010;51:806-12.

13. Nigam RK, Malik R, Kothari S, Gour D, Shrivastava A, Balani S, et al. "Spectrum of Diseases Diagnosed by Bone Marrow Examination in Central India". Journal of Evolution of Medical and Dental Sciences. 2014;3(2):326-37.

14. Chandra S, Chandra H. Comparison of bone marrow aspirate cytology, touch imprint cytology and trephine biopsy for bone marrow evaluation Hematol Rep. 2011;3(3):e22.

15. Parajuli S, Tuladhar A. Correlation of bone marrow aspiration and biopsy findings in diagnosing hematological disorders - a study of 89 cases. Journal of Pathology of Nepal. 2014;4:534-8.

16. Khan TA, Khan IA, Mahmood K. Diagnostic role of bone marrow aspiration and trephine biopsy in haematological practice. $\mathrm{J}$ Postgrad Med Inst.2014;28(2):217-21.

Copyright: (C) the author(s), 2019. It is an open-access article distributed under the terms of the Creative Commons Attribution License (CC BY 4.0), which permits authors to retain ownership of the copyright for their content, and allow anyone to download, reuse, reprint, modify, distribute and/or copy the content as long as the original authors and source are cited.

How to cite this article: Rathore SS. A Prospective Study to Assess the Bone Marrow Aspiration for Findings of Patients with Hematological Disorders. Asian J. Med. Res. 2019;8(2):PT04-PT06.

DOI: dx.doi.org/10.21276/ajmr.2019.8.2.PT2 